\title{
Nutritional Status
}

National Cancer Institute

\section{Source}

National Cancer Institute. Nutritional Status. NCI Thesaurus. Code C17993.

The state of the body as influenced by the diet and the ability of the diet to maintain an overall healthy condition. 